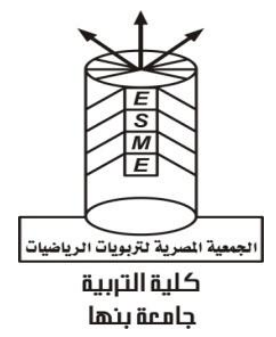

atho

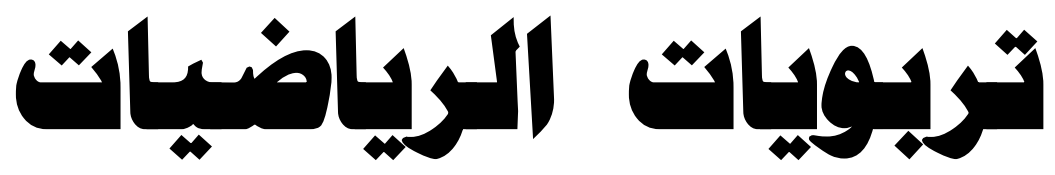

(مجلة بثثية حلمية محكهة)

هيئة التمرير

\begin{tabular}{|c|c|c|}
\hline الكلية والجامعة & الاسم & 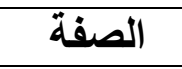 \\
\hline التربية - عين شمس & أ.د.محمد أمين المفتي & 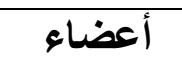 \\
\hline التربية - بنه & أ.د.بعلاء اللاين سعد متولَي & التحرير \\
\hline التربية ـ المنوفية & أ.د.فتيحة أحمد بطيخ & \\
\hline اللدراسات العليا للتربية ـ القاهرة & أ.د.و ائل عبدالله محمد علي & \\
\hline التربية ـ الملكك سعود & أ.د. هشام بركات حسين & \\
\hline التربية - الطفيلية - الأردن & أ.د.تيسير خليل القيسي & \\
\hline التربية - ميسان - العراق & أ.د.عمار طعمه الساعدي & \\
\hline التربية ـ الفيوم & أ.م.د.أحمد إبراهيم خطاب & \\
\hline التربية ــ بنهــــ & دـإبراهيم التونسي السيد & نانب رئيس \\
\hline التربية - بنه & أ.د. العزب محمد زهـران & رئيس التحرير \\
\hline
\end{tabular}

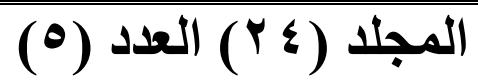

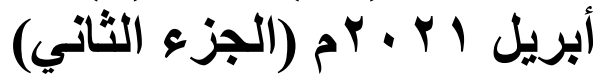




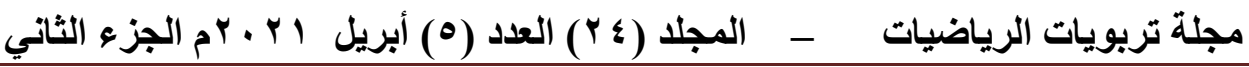

\section{هبلة تربويات الرياضيات}

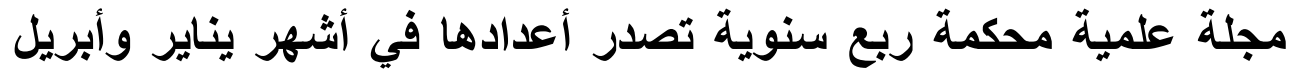

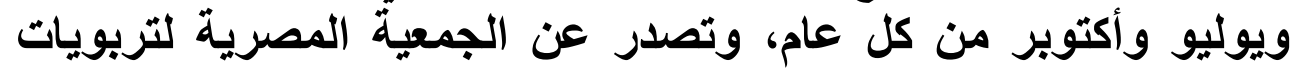

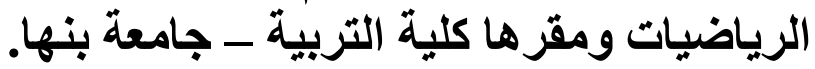

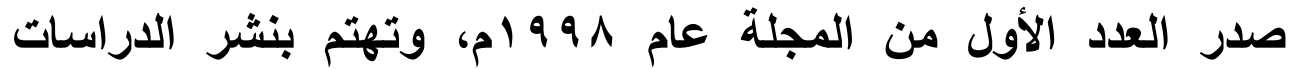

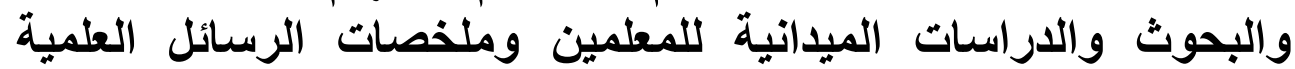

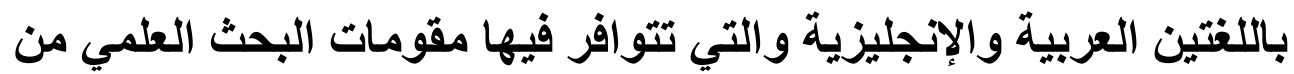

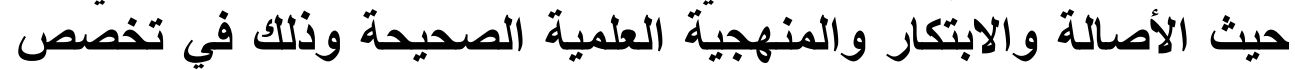

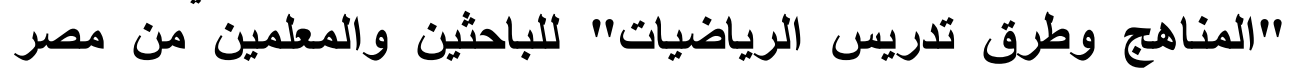

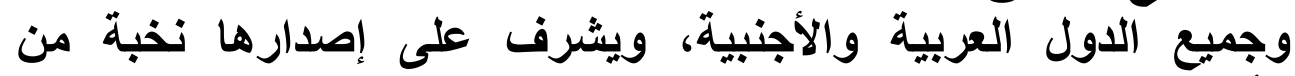

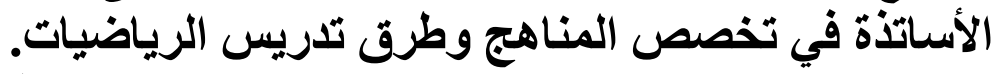

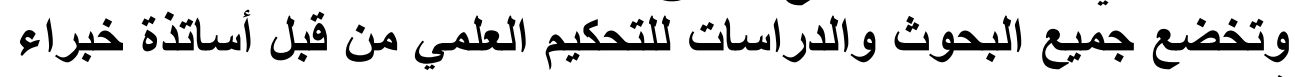

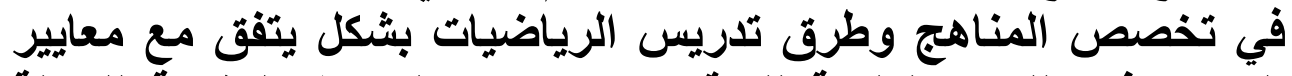

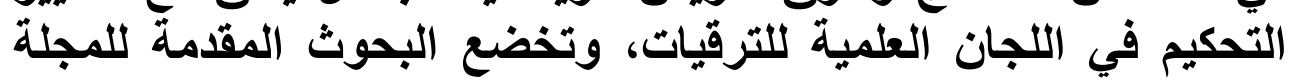
لبرنامج الانتحال العلمي.

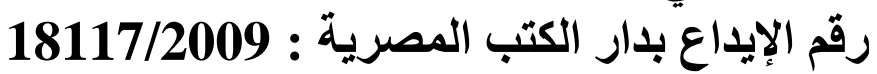

(Print) : (ISSN 2090 - 0562)

(Online) : (ISSN 2682- 4337)

الموقع على بنك المعرفة المصري

http://armin.journals.ekb.eg/

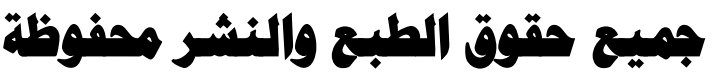

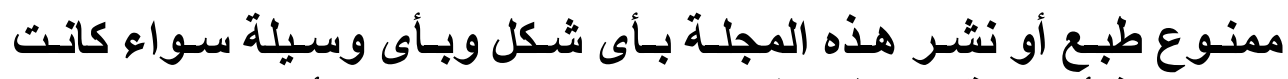

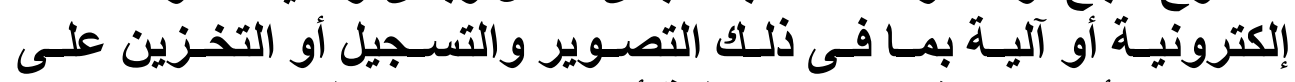

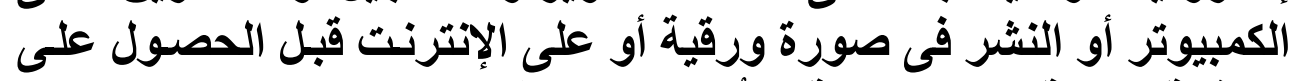

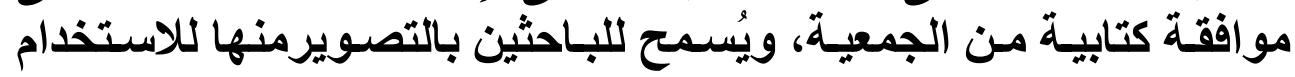
الشخصى لغرض البحث العلمى.

EM: mathedu1997@ hotmail.com كلية التربية - جامعة بنها لئية 


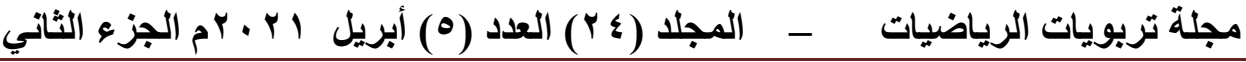

\section{قواعد النششر بلإلمبة}

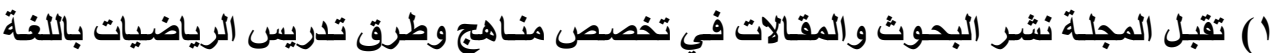

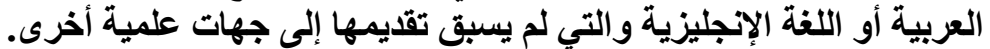

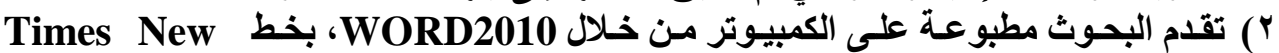

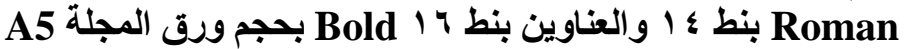

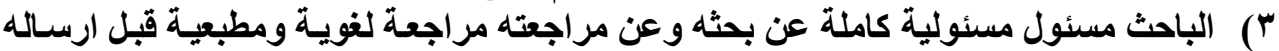

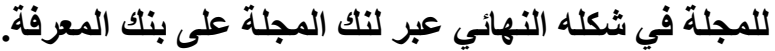

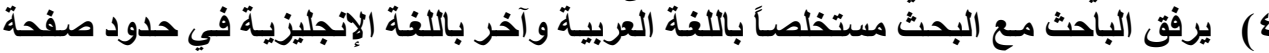

واحدة للمستخلصين معا.

0) يكتب الباحث اسمه وجهة عمله ووظيفته وبريده الإكتروني وعنوان البحث باللغتين العربية

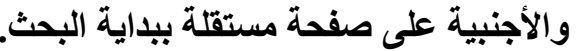

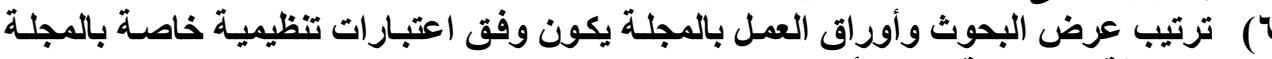

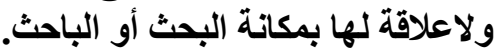

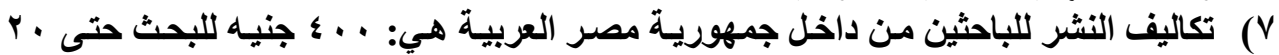

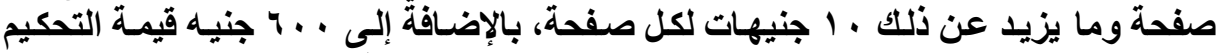

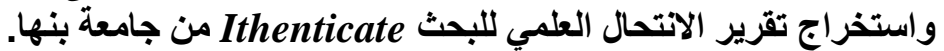

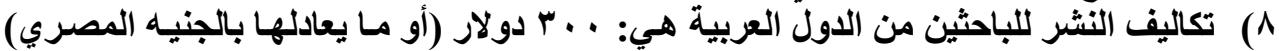

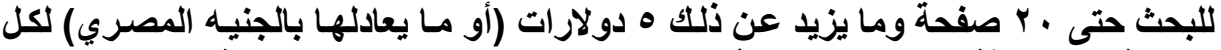

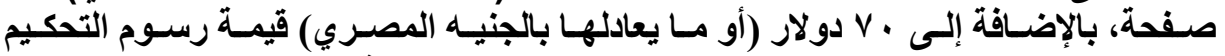

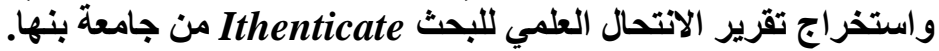

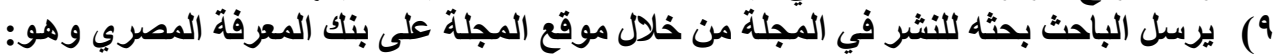
http://armin.journals.ekb.eg/

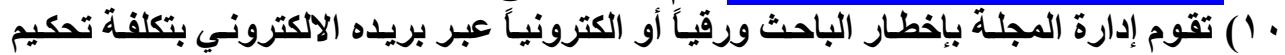

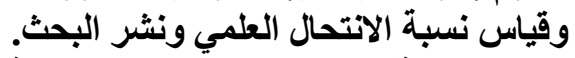
1) (1) تعيد المجلة البحث إلى الباحثث للمراجعة والتعديل إذا زادت نسبة الانتحال العلمي بـه عن \% ro

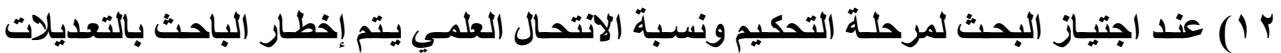

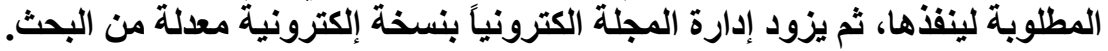

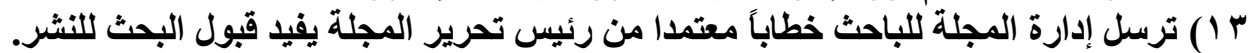

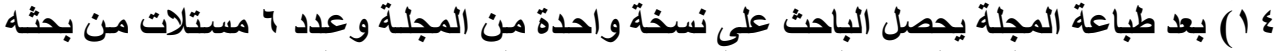

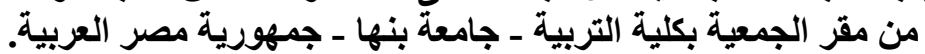

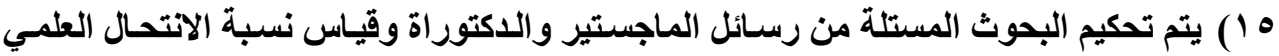

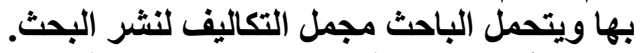

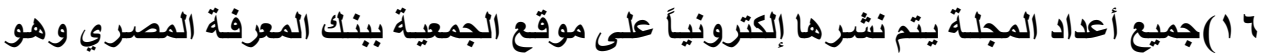
با http://armin.journals.ekb.eg/ بنظام PDF من على موقع المجلة. 


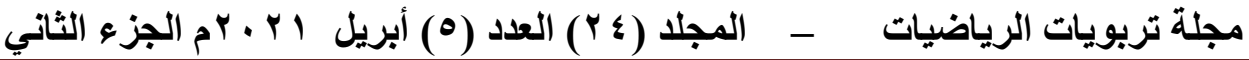

\section{الميستة الاستشارية لتمكيم بصمث اللهالة \\ (مرثبون أبجدياً)}

\begin{tabular}{|c|c|c|c|c|}
\hline 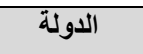 & الجامعة & البريد الاكتروني & الاسم كاملا بالعربية & \\
\hline الاردن & الجامعة الأردنية & i.shara@ju.edi.jo & أ.د/ ابراهيم احمد الثرع & .1 \\
\hline 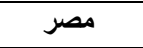 & جامعة الزقازيق & drebrahimattia@yahoo.com & أ.د/ ابراهيم أحمد السيد عطية &.$r$ \\
\hline 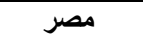 & جامعة بورسعيد & Imrefaat72@yahoo.com & أ.د/ ابراهيم رفعت إبراهيم &.$r$ \\
\hline السعودية & جامعة شقراء & amabdullah@su.edu.sa & أ.د/ ابراهيم محمد عبدالله &.$\varepsilon$ \\
\hline مصر - إ & جامعة طنطا & i.shara@ju.edi.jo & أ.د/ ابراهيم حسن عساف &.$\circ$ \\
\hline مصر & جامعه المنيا & amoustaf@hotmail.com & أ.د/ أحمدالسيد مصطفي & .7 \\
\hline 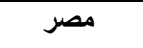 & جامعة طنطا & dr.ahmedr@edu.tanta.edu.eg & أ.د/ أحمد محمد الرفاعي &. $\mathrm{V}$ \\
\hline 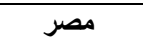 & جامعة بنها & alazabzahran@hotmail.com & أ.د/ العزب محمد زهران &.$\wedge$ \\
\hline مصر & المركز القومي للامتحانات والتقويم & abarashedd@yahoo.com & أ.د/ أشرف راشد علي & .9 \\
\hline السعودية & جامعة أم القزى & I_h_assaf@hotmail.com & أ.د/ بشينة محمد بلر & $.1 \cdot$ \\
\hline الأردن & جامعة الطفيلة التقتية & D_qaysee@hotmail.com & أ.د/ تيسير خليل بخيت القيسي & .11 \\
\hline 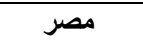 & جامعة سوهاج & gamalhamid77@yahoo.com & أ.د/ جمال حامد محمد منصور & .14 \\
\hline مصر - مصر & جامعة أسيوط & fkryabo@yaboo.com & أ.د/ جمال محمد فكري خليفة & $.1 T$ \\
\hline السعودية & جامعة الملك خالد & dr_hamza@hotmail.com & أ.د/ حمزة عبد الحكم الرياشي & $.1 \leqslant$ \\
\hline السعودية & جامعة الامـام محمد بن سعود & kalkhuzaim@gmail.com & أ.د/ خالد محمد ناصر الخزيم & .10 \\
\hline الأردن & جامعة آل البيت & khnejem@yahoo.com & أ.د/ خميس موسى خميس نجم & .17 \\
\hline سلطنة عمان & جامعة السلطان قابوس & abuelwan@squ.edu.om & أ.د/ رضا ابوعلوان السبي & $.1 \mathrm{~V}$ \\
\hline 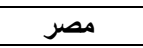 & جامعة بنها & abouserie@ hotmail.com & أ.د/ رضا عبدالله أبو سريع & .11 \\
\hline 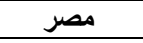 & جامعة دمياط & Rmasar@ hotmail.com & أ.د/ رضا مسعد السعيد عصر & .19 \\
\hline مصر & أسيوط & Refaatelmeligy@yahoo.com & أ.د/ رفعت محمد المليجي &.$r \cdot$ \\
\hline مصر & جامعه المنيا & Z_2004eg@yahoo.com & أ.د/ زينب أحمد عبد الغتي & .1 \\
\hline مصر & جامعة اسيوط & zotiefy@yahoo.com & أ.د/ زينب محمود عطيفي &.$M r$ \\
\hline 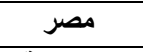 & جامعة المنوفية & sgmenoufy@yahoo.com & أ.د/ سعيد جابر المنوفي & $\mathrm{HT}^{\mathrm{r}}$ \\
\hline السعودية & جامعة الملك سعود & Salshalhoub@ksu.edu.sa & أ.د/ سمر عبدالعزيز الشلهوب & $. r \leqslant$ \\
\hline مصر & جامعة قناة السويس & shabanhefny@hotmail.com & أ.د/ شعبان حفني شعبان & .90 \\
\hline مصر & جامعة قناة السويس & shabanhefny@hotmail.com & أ.د/ شعبان حفني شعبان & .47 \\
\hline مصر & جامعة عين شمس & Shreen.salah@yahoo.com & أ.د/ شيرين صلاح عبد الحكيم &. $\mathrm{YV}$ \\
\hline الاردن & الجامعة الأردنية & h2000hrty@gmail. Com & أ.د/ صبري محمد حتوت &. $\mathrm{r}$ \\
\hline السعودية & جامعة طيبة ، السعودية & tsalharbi@hotmail.com & أ.د/ طلال الحربي & .99 \\
\hline السعودية & جامعة الملك خالد & alshehri2014997@gmail.com & أ.د/ ظافر فراج هزاع الثهري & $\cdot r \cdot$ \\
\hline مصر & جامعة الزقازيق & adelalbaz@yahoo.com & أ.د/ عادل إبراهيم الباز &.$r 1$ \\
\hline السعودية & جامعة تبوك & Aa.albalawi@ut.edu.sa & أ.د/ عايد بن علي البلوي & 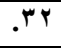 \\
\hline 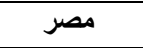 & جامعة الزقازيق & Hah_mrmr2003@ hotmail.com & أ.د/ عايدة سيد هم إسكندر &.$r r$ \\
\hline 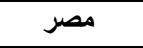 & جامعة دمياط & Prof41260@yahoo.com & أ.د/ عبد الناصر أنيس عبدالوهاب &.$r \varepsilon$ \\
\hline السعودية & جامعة حائل & a.altamimi5@gmail.com & أ.دد/ عبدالرحمن ابراهيم التميمي &.$r \Delta$ \\
\hline
\end{tabular}




\begin{tabular}{|c|c|c|c|c|}
\hline 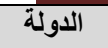 & الجامعة & البريد الالكتروني & الاسم كاملا بالعربية & \\
\hline 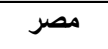 & جامعة بنها & lana_dana2005@yahoo.com & أ.د/ عبدالقادر محمد عبدالقادر & 4 \\
\hline مصر & جامعة عين شمس & Drazza2006@yahoo.com & أ.د/ عزة محمد عيد السميع &.$r v$ \\
\hline مصر & جامعة بنها & dralaasaad2014@gmail.com & أ.د/ علاء الدين سعد متولي &.$r \Lambda$ \\
\hline 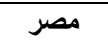 & جامعة الزقازيق & aabdelrahim@gmail.com & أ.د/ على عبد الرحيم حساتين &.$r q$ \\
\hline العراق & جامعة ميسان & atjsm2005@yahoo.com & أ.د/ عمار طعة جاسم الساعدي &. \\
\hline مصر & جامعة أسيوط & tdary6000@yahoo.com & أ.د/ عوض حسين التودري &.$\leqslant 1$ \\
\hline السعودية & جامعة ام القرى & Uqusmt@gmail.com & أ.د/ عوض صالح المالكي &.$\leqslant Y$ \\
\hline مصر & جامعة بورسعيد & tamtam_hadid@yahoo.com & أ.د/ فاطمة عبد السلام ابو الحديد &.$\leqslant r$ \\
\hline مصر & جامعة عين شمس & fmmina@link.net & أ.د/ فايز مراد مينـا &.$\leqslant \varepsilon$ \\
\hline 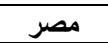 & جامعة أسيوط & Fayzahamada33@gmail.com & أ.د/ فايزة احمد محمد حمادة &.$\leqslant 0$ \\
\hline مصر & جامعة المنوفية & fatiha_batikh@yahoo.com & أ.د/ فتيحة أحمد بطيخ & .87 \\
\hline مصر - مصر & جامعة دمياط & Maths_proff@yahoo.com & أ.د/ فريال عبده عبده أبو ستة &.$\leqslant V$ \\
\hline الأردن & جامعة عمان العربية & zfhalshehri@hotmail.com & أ.د/ فريد كامل أبوزينة &.$\leqslant \Lambda$ \\
\hline 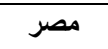 & جامعة المنصورة & fouadmm50@yahoo.com & أ.د/ فؤاد محمد موسى &.$\leqslant 9$ \\
\hline مصر & جامعة الاسكندرية & magda33saleh@yahoo.com & أ.د/ ماجدة محمود صالح & .0 \\
\hline 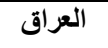 & جامعة بغداد & dr.mejbel.aljouani@gmail.com & أ.دد/ مجبل حماد عواد الجوعاني & .01 \\
\hline مصر & جامعة عين شمس & elmofti44@ hotmail.com & أ.د// محمد أمين المفتى & $.0 Y$ \\
\hline السعودية & جامعة الملك سعود & alnatheer@ksu.edu.sa & أ.د/ محمد بن عبدالله النذير & $.0 \mathrm{~T}$ \\
\hline مصر & جامعة المنيا & prof.r_58@yahoo.com & أ.د/ محمد ربيع حسني & $.0 \leqslant$ \\
\hline 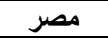 & جامعة دمياط & dr.hasaballa@gmail.com & أ.دد/ محمد عبد الحليم حسب الله & .00 \\
\hline مصر & جامعة بنها & mibadr@gmail.com & أ.د/ محمود إيراهيم بدر & .07 \\
\hline مصر & جامعة بني سويف & m_nasr1010@yahoo.com & أ.د/ محمود أحمد نصر & $.0 \mathrm{~V}$ \\
\hline مصر - ا مصر & جامعة أسيوط & mhawad2000@yahoo.com & أ.د/ محمود حسن عوض & .01 \\
\hline مصر & جامعة الزقازيق & morad1955@hotmail.com & أ.د/ محمود عبد/للطيف مراد & .09 \\
\hline 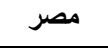 & جامعة أسيوط & mhawad2000@yahoo.com & أ.د/ محمود محمد حسن عوض & .7. \\
\hline 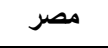 & جامعة بنى سويف & madihahm2004@yahoo.com & أ.د/ مديحة حسن محمد & .71 \\
\hline 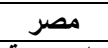 & جامعة عين شمس & drmervat23@yahoo.com & أ.بد/ مرفت محمد كمال & .74 \\
\hline 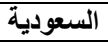 & جامعة الملك سعود & misfer5@yahoo.com & أ.ـد/ مسفر بن سعود السلولي & .74 \\
\hline مصر & عين شس & Makka.elbanna@women.asu.edu.eg & أ.د/ مكة عبد المنعم البنا & $.7 \varepsilon$ \\
\hline مصر - مصر & جامعة طنطا & nagimichael@hotmail.com & أ.د/ ناجي ديسقورس ميخائيل & .70 \\
\hline 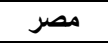 & جامعه طنطا & Nabilahimaya@ hotmail.com & أ.د/ نبيله زكى ابراهبم & .77 \\
\hline 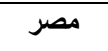 & جنوب الوادي & nasrmowd@gmail.com & أ.دد/ نصر الله محمد محمود معوض & $.7 \mathrm{~V}$ \\
\hline 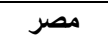 & جامعة عين شمس & info@nazla-khedre.com & أ.د/ نظلة حسن خضر & .71 \\
\hline السعودية & جامعة الأميرة نورة بنت عبد الرحمن & Dr.nawal123@hotmail.com & أ.بد/ نوال محمد الراجح الغنقري & .79 \\
\hline 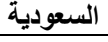 & جامعة الملك سعود & hbisher@hotmail.com & أ.د/ هشام بركات بشر حسين &.$v$. \\
\hline مصر & جامعة القاهره & drwaelabdallah@gmail.com & أ.دد/ وائل عبد الله محمد على &.$\vee 1$ \\
\hline 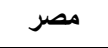 & جامعة القاهره & wmkefafe@cu.edu.eg & أ.د/ وفاء مصطفى محمد كفافي &.$V Y$ \\
\hline 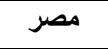 & جامعه المنيا & dryasmenzedan@yahoo.com & أ.د/ ياسمين زيدان حسن &.$V \mu$ \\
\hline مصر | - | - مصر & جامعة طنطا & dr.yelemam@gmail.com & أ.د/ يوسف الحسيني الامام &.$V \varepsilon$ \\
\hline $\begin{array}{l}\text { USA } \\
\end{array}$ & $\begin{array}{c}\text { University of Nevada } \\
\text { Las Vegas } \\
\end{array}$ & william.speer@unlv.edu & $\begin{array}{r}\text { Professor Dr.William } \\
\text { Renwick Speer } \\
\end{array}$ &. $\mathrm{V}^{\circ}$ \\
\hline
\end{tabular}




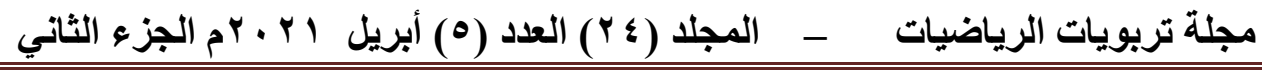

\section{טnell}

() المنهج المختلط : مدخل تكاملي لامج البيانات الكمية والنوعية في البحث التربوي. إعداد: أ.د. رضا مسعد السعيا ....................

التفكير الهندسي وعلاقته بالذاكرة العاملة البصرية ـ المكانية والتحصيل الدراسي

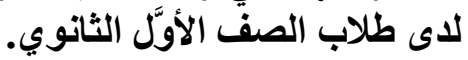

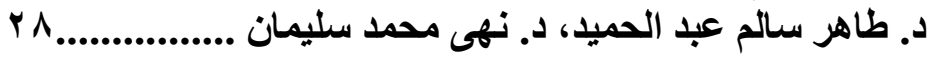

ץ) دور التعليم الإتقاني في تعزيز مستوى التحصيل في الرياضيات مع نموذج تطبيقي

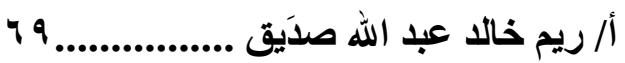
على تلاميذ الصف السنادس الابتدائي.

ع) تحسين بناء الفهم الجبري وترقيته لتلاميذ الصف الثاني الإعدادي في بيئة تعلم تستند الي التمثيلات الرياضية.

1.1 أز فاطمة حماده بسيوني أبو صيرة

•) برنامج مقترح قائم على المنطق الرياضي لتنمية مهارات الإثبات الجبري للى تلاميذ المرحلة الاعدادية.

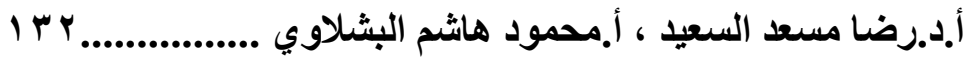

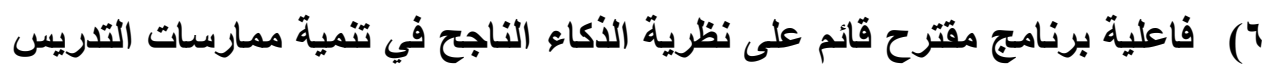

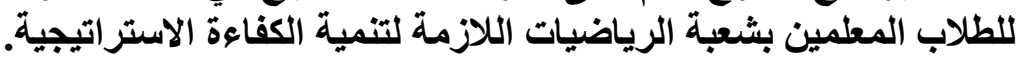
أ.م.د سامية حسنين عبد الرحمن هلال ................. • 17

(V واقع ممارسات معلمي الرياضيات عن بعد لتلبية احتياجات الطلبة الموهوبين: 197 Praxeology اكتشاف معات ^) الاحتياجات التذريبية لمعلمي الرياضيات في ضوء مهارات معلم القرن الحادي Y19

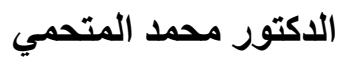
والعشرين. 
